\title{
PAUL RICOEUR Y UNA VIDA BUENA CON OTROS Y PARA OTROS: A PROPÓSITO DEL TRABAJO EN EQUIPO EN SALUD
}

\author{
María Eugenia Rapimán Salazar ${ }^{1}$, Irene Alicia Acevedo Pérez², Mauricio Adrián Osorio Ulloa ${ }^{3}$, Adrián \\ Darío Torres Canales ${ }^{3}$
}

Resumen: Este artículo revisa aspectos esenciales del trabajo de equipo, en el ámbito de salud, desde la perspectiva ética de Paul Ricoeur. La ética, conceptualizada por este autor como "tender a una vida buena con otros y para otros dentro de instituciones justas", constituye una alternativa de reflexión, análisis y discusión del fundamento ético del trabajo en equipo en salud, y conmina a sus miembros a cimentar y/o rediseñar las bases para la articulación y aplicación de esta intencionalidad de vida buena con otros y para otros en su cotidianidad. El trabajo en equipo es una instancia en la que el ser humano, en intersubjetividad, desarrolla su modo de ser ético y construye su experiencia moral. En la medida en que cada miembro desarrolle y ejercite una permanente interpretación de sí mismo y de su accionar, conducente a la estima de sí y a su autovaloración, podrá contribuir a establecer mejores espacios de convivencia y de trabajo con otros.

Palabras clave: Paul Ricoeur, modo de ser ético, estima de sí mismo, autovaloración, trabajo en equipo en salud, instituciones justas

Paul Ricoeur and with a good and other life other: a purpose of teamwork in health

\begin{abstract}
This article essential aspects of teamwork in the field of health, are reviewed from the ethical perspective of Paul Ricoeur. Ethics conceptualized by the author as "tending to a good life with others and for others in just institutions", is an alternative for reflection, analysis and discussion the ethical foundation of teamwork in health, and urges its members to build and / or redesign the bases for the articulation and implementation of this intentionality of good life with others and others in their daily lives. Teamwork is an instance in which the human being in intersubjectivity with others, develops his way of being ethical and moral constructs his experience. To the extent that each member develop and exercise permanent interpretation of himself and his actions leading the esteem and their self-esteem, may help establish better living spaces and working with others.
\end{abstract}

Keywords: Paul Ricoeur, ethical way of being, self-esteem, self-worth, teamwork in health, just institutions

\section{Paul Ricoeur e com boa e outra vida outros: um fim dos trabalhos de equipa em saúde}

Resumo: Este artigo aspectos essenciais do trabalho em equipe no campo da saúde, são analisados a partir da perspectiva ética sobre Paul Ricoeur. Ética conceituada pelo autor como "tendendo para uma boa vida com os outros e para os outros em instituiçóes justas", é uma alternativa à reflexão, análise e discussão o fundamento ético do trabalho em equipe na saúde, e insta seus membros para construir e / ou reformular as bases para a articulação e implementação deste intencionalidade boa vida com os outros e para os outros em suas vidas diárias. Trabalho em equipe é um caso em que o ser humano em intersubjetividade com os outros, desenvolve a sua maneira de ser construçóes éticas e morais sua experiência. Na medida em que cada membro desenvolver e exercitar uma interpretaçáo permanente de si mesmo e suas ações que levam a auto-estima e sua auto-estima, você pode ajudar a criar melhores espaços de vida e trabalhar com os outros.

Palavras chave: Paul Ricoeur, forma ética de estar, auto-estima ou auto-estima, trabalho em equipe na saúde, instituiçôes justas

\footnotetext{
${ }^{1}$ Escuela de Enfermería. Universidad Diego Portales, Santiago Chile

Correspondencia: mrapiman@gmail.com

${ }^{2}$ Universidad Diego Portales, Santiago Chile

${ }^{3}$ Escuela de Medicina. Universidad de Santiago de Chile, Chile
} 


\section{Introducción}

En el trabajo en equipo, subyace la idea de que, mediante un esfuerzo conjunto, coordinado e interdependiente, sus miembros aspiran al logro de un objetivo común. Esto, por una parte, conlleva la noción de que, en este esfuerzo coordinado, cada integrante deba someterse a algún tipo de autoridad y también deja implícito que, para mantener la independencia y lograr el objetivo común, sus miembros deban estar regidos por el mismo marco normativo, que asegure su integración(1).

En el ámbito de salud, este esfuerzo conjunto, coordinado e interdependiente se orienta en la actualidad a la satisfacción de necesidades de salud de la población y el fomento de la misma. Esto implica considerar al ser humano individual y colectivamente de forma holística, dentro de un contexto socioantropológico, cuyos factores determinan sus necesidades de salud(2). Los integrantes del equipo multidisciplinario de salud están conminados a transitar desde una praxis permeada y fundamentada, desde larga data, en el paradigma positivista, caracterizada por la realización de actividades procedimentales, la ejecución de técnicas específicas, orientadas a la recuperación de la función de órganos, hacia un paradigma que reconoce al otro como un ser humano, que toma en cuenta sus necesidades personales, sus valores y sus sentimientos, y que, en definitiva, es capaz de construir su propio cuidado(3).

Este cambio en el paradigma que orienta la acción en salud, hace imprescindible la construcción y mantención de relaciones y transacciones interpersonales sólidas entre los miembros del equipo, con otros profesionales sanitarios, con el personal, y con el ser al que se debe cuidar y procurar satisfacer sus necesidades de salud. De ahí que el ethos, entendido como el "carácter", "modo de ser" y "forma de vida" que cada miembro del equipo porta en sí, o tiene en sí mismo (su morada interior) y la disposición que asume ante sí, y ante los otros miembros del equipo(4), cobra especial relevancia.

El propósito de este artículo es aportar a la reflexión, en torno al fundamento filosófico que debería tener el trabajo en equipo, en el ámbito de salud, a partir del nuevo paradigma.

\section{Paul Ricoeur y una vida buena con otros y para otros}

Paul Ricoeur (1913-2005), teniendo como referente algunos elementos centrales de la teleología Aristotélica — aspiración a una vida buena- y de la deontología kantiana, que persigue la definición de lo correcto, de aquello que se ajusta a la ley, distingue tres momentos en la ética global: la ética; la moral y la sabiduría práctica(5-10).

La ética es definida por este filósofo como la intencionalidad de una vida realizada, que se expresa como el objetivo de "tender a una vida buena con otros y para otros, dentro de instituciones justas". Aquí el término "vida" es considerado en su sentido ético-cultural, que va más allá del sentido puramente biológico, y que designa al hombre en su totalidad. Según Ricoeur, la palabra "vida" recibe la dimensión apreciativa, valoradora del ergon (función) que califica al hombre en cuanto tal, y destaca este autor que el ergon del hombre corresponde al plan de vida, aquello que Sócrates en su tiempo designó como "proyecto existencial" (7-10).

Con el término "vida buena" hace referencia a la totalidad de la vida del hombre, la que correspondería a los ideales y sueños de realización, respecto de lo cual una vida es considerada como más o menos realizada, o como no realizada. Plantea que cada praxis tiene un fin en sí misma y que toda acción tiende hacia un fin último, y el secreto del encaje de las finalidades reside en la relación entre práctica y plan de vida. Así, la vida buena es el objetivo mismo de la intencionalidad ética (el fin último de la acción)(7-10).

Destaca que esta intencionalidad de vida buena, como objetivo hacia el que tienden las acciones o prácticas (que tienen su fin en ellas mismas), exigiría al hombre un permanente trabajo de interpretación de sí mismo y de su accionar, es decir la aspiración a una vida buena incluye un trabajo incesante de interpretación de la acción y de sí mismo, en el que se persigue la búsqueda de adecuación entre lo que nos parece lo mejor para el conjunto de nuestra vida y las elecciones preferenciales que rigen nuestras prácticas. Pro- 
duciéndose, según Ricoeur, un vaivén entre el objetivo ético de vida buena y las elecciones particulares, como es, por ejemplo, la elección de una carrera. Es a este ir y venir entre el objetivo ético de vida buena y las elecciones particulares al que Ricoeur da el nombre de "círculo hermenéutico" y señala que esto sucede como un texto en el que el todo y la parte se comprenden uno a través del otro. Agrega que interpretar el texto de la acción es para el agente interpretarse a sí mismo. Así, tender a una vida buena conduciría a la estima de sí, que no es otra cosa que la autovaloración del sí mismo. Dice que, en la medida en que apreciamos nuestras acciones, nos apreciamos a nosotros como autores de estas.

Otro aspecto importante es que la estima de sí o autovaloración del sí mismo no ocurriría en solitario, sino en un tiempo y espacio compartido con otros, es decir, en una interrelación, y es precisamente ese otro, distinto de sí (que es un rostro visible), al que Ricoeur acuña bajo el concepto de "solicitud". Con esta denominación añade la idea de "carencia de ese otro", muchas veces sufriente, y que, bajo esta condición, es capaz de activar esa espontaneidad benévola, ligada íntimamente a la estima de sí $(7,8,10)$.

La repercusión que tendría la solicitud sobre la estima de sí, es que el sí se percibe a sí mismo como otro entre los otros. Esto significa asumir que el otro también es capaz de comenzar algo en el mundo, de actuar por determinadas razones, de jerarquizar sus preferencias y, de este modo, estimarse a sí mismo como uno se estima a sí mismo. De esta forma, según Ricoeur, se convierten en equivalentes la estima del otro como sí mismo y la estima de sí mismo como otro. Pero la intencionalidad de la vida buena, la estima de sí, que parte en un espacio de relaciones interpersonales, no se limita solo a este espacio de convivencia, sino que también se hace extensible a la convivencia en la comunidad con otros anónimos, que muchas veces no son rostro visible para el sí mismo. A esta estructura de vivir juntos en una comunidad histórica Ricoeur la denomina "instituciones", las que, según este autor, se caracterizan esencialmente por poseer costumbres comunes y no por tener reglas coaccionantes. De ahí que, ante la multiplicidad de intenciones de vidas buenas, las instituciones requieren de una normativa moral que procure espacios de igualdad para todos sus miembros. Al respecto argumenta que la igualdad es a la vida en las instituciones, como la solicitud a las relaciones interpersonales, y así como la solicitud da como compañero del sí otro que es un rostro, la igualdad da como compañero otro que es un cada uno. Destaca, además, que el sentido de la justicia supone la solicitud, en la medida en que considera a las personas como irreemplazables y acrecienta la solicitud, en cuanto que el campo de aplicación de la igualdad es toda la humani$\operatorname{dad}(7)$.

En cuanto a la moral — segundo momento de la ética global-, este autor usa este concepto para la articulación de la intencionalidad — "tender a una vida buena con otros y para otros dentro de instituciones justas" - dentro de normas, caracterizadas a la vez por la pretensión de universalidad, es decir, en esta instancia el autor somete la intencionalidad ética a la rigurosidad de la ley. En esta intencionalidad el respeto del otro y de sí mismo como otro, la libertad y la igualdad se constituyen en valores fundamentales. Especifica que, siendo la libertad y la igualdad valores contrapuestos, si se privilegia la libertad, hay que resguardar la igualdad. De ahí la importancia y/o pertinencia del rigor de una moral de estilo kantiana, es decir, lo necesario que es actuar de acuerdo con una máxima que guíe la acción, evitando así la arbitrariedad en la praxis humana. Lo justo pasa a constituirse en la aspiración, en el objetivo ético que va a ser fundamento de obligación moral. Tiene su inspiración en la vida misma: no se trata de respetar una ley por mero respeto a la ley $(7,9)$.

Respecto de la sabiduría práctica, plantea que esta correspondería a la toma de decisiones, intentando aplicar la ley a los casos concretos particulares, lo que Ricoeur llama el "juicio moral en situación". Esto porque, según el autor, la complejidad de los conflictos en la moralidad llama a un pensar justo. Allí, frente a la rigurosidad de la ley, que no contempla la particularidad diferenciadora de cada caso concreto, se hace necesario, para llegar a una toma de decisiones, el retorno al momento propiamente ético de la intención de una vida buena con otros y para otros dentro de instituciones justas, en busca de los criterios que permitan dilucidar la legitimidad de posibles excepciones en la aplicación de la norma. A veces se da el con- 
flicto moral y es necesaria la excepción(7).

\section{Discusión}

En línea con el planteamiento de Paul Ricoeur, la imagen de sí mismo y la estima de sí que tenga cada uno de los integrantes del equipo de salud, se constituyen en aspectos centrales para la construcción y desarrollo de la experiencia intersubjetiva al interior del equipo de trabajo.

La imagen de sí mismo, entendida como un retrato de uno mismo, tal como uno se percibe, da una identidad que intenta ser comprendida y captada por los demás. Esta imagen es variada y está compuesta por representaciones de naturaleza diferente (cognitivas, afectivas), referentes al yo pasado, al actual y al futuro. Es un constructo que se fragua, evoluciona y fortalece a medida que interactuamos con otros; influye en nuestra opinión acerca de los demás; nos guía en la elección de nuestras interacciones sociales y en las estrategias que utilizamos en el curso de estas interacciones, y determina también nuestra forma de reaccionar frente a informaciones sobre nosotros, dadas por otros. De ahí que la riqueza, la flexibilidad y la pluralidad de la imagen que se tenga de sí mismo puede ser considerada como un elemento clave para la eficacia del trabajo en equipo. Esto confirma el planteamiento de Ricoeur respecto de la importancia que tiene para la convivencia humana, tanto en el ámbito cotidiano como en el profesional, que cada persona realice un permanente e incesante trabajo de interpretación de sí mismo y que, de acuerdo con esto, vaya engranando en un todo coherente y de sentido su plan de vida (proyecto existencial) con su praxis profesional, lo que conduciría, según este filósofo, a la estima de sí mismo.

La estima de sí, entendida como la dimensión afectiva y evaluativa de la representación que se tenga, implica un juicio de valor que puede ser general, y que se establece en comparación con un yo ideal; o también puede ser específico y definido en relación con las exigencias de la tarea a la que uno se enfrenta. De acuerdo con esto, las experiencias profesionales, en el ámbito de salud, desempeñan un papel importante y diversificado en el fortalecimiento de la autoestima. Considerando que, cuanto más variado es el trabajo más competencias de alto nivel implica, cuanto más permite ser autónomo, participar en las decisiones, perfeccionarse al adquirir nuevas competencias; y cuanto mejor son las relaciones con los colegas, los subordinados y los superiores, más generador de autoestima es.

Se tiene que la plasticidad de la estima de sí depende del grado de estima que uno se tenga. Aquellos cuya estima es débil, están mucho más dispuestos a modificar la opinión que tienen de sí mismos que aquellos que se han construido una opinión más favorable; porque tener una autoestima débil implica una falta de confianza en las propias opiniones y le hace a uno más abierto a lo que afirman los demás. Una autoestima débil es otra forma de decir que uno no se quiere y de expresar una gran necesidad de ser aprobado y de ser reafirmado. Esto equivale a conformarse con los comportamientos de los demás y a aceptar sus opiniones con la esperanza de recibir valoraciones positivas. Las personas con autoestima débil tienen una identidad menos sólida y están, por lo tanto, más dispuestas a aceptar lo que los demás dicen de ellas.

Esto corrobora el planteamiento de Ricoeur, específicamente cuando señala que, en la medida que apreciamos nuestras acciones, nos apreciamos a nosotros mismos como autores de estas (las acciones); que tender a una vida buena conduciría a la estima de sí, y que esto no es otra cosa que la autovaloración del sí mismo. Además, que la autovaloración del sí mismo ocurriría en un espacio compartido con otros, donde en ocasiones estos elementos (imagen de sí mismo y estima de sí) podrían no estar armónicamente integrados en la experiencia subjetiva de ese otro, dejándolo en condición de carencia, lo que este filósofo conceptualiza como "solicitud".

Así, cuando en un equipo de trabajo uno de sus integrantes se encuentra en condición de "solicitud" y requiere de la atención o ayuda de los otros integrantes del equipo, habitualmente es el líder quien está llamado a estar especialmente atento a no dejar pasar esa instancia, porque la valoración que de él se tiene dentro del equipo le transforma en principal actor para el fortalecimiento individual del requirente, tanto en la autoimagen como en la autoestima. Es él quien está llamado a asumir 
la responsabilidad de regular, modular y adecuar sus intervenciones, a los espacios de convivencia con otros; tiene la tarea o misión de ordenar el trabajo propiamente tal, planificar su ejecución y, lo que es primordial, buscar las mejores potencialidades en cada uno de estos integrantes, los cuales individualmente tienen sus propias imágenes y estimas. Se transforma, entonces, en el que debe buscar lo mejor de cada uno de ellos y colocarlo al servicio del objetivo que este equipo de salud se ha trazado. En ambos casos funcionarán como retroalimentación positiva, generando mayores grados de autovaloración en ambas dimensiones, lo cual fortalece no solo al individuo, sino que de igual forma al colectivo integralmente; $y$, por extensión, también funciona desarrollando aún más al líder. Sin embargo, es real la posibilidad de que el líder también pudiese estar afectado en su autovaloración, por lo que se debe atentos como grupo a entregarle la ayuda requerida; pero, también él, actuar positivamente enfrentando esta dificultad.

Finalmente, podríamos entender que lo ya comentado podría ser un aspecto de la resiliencia, la que podemos también analizar claramente desde un componente individual, en la cual cada uno de los integrantes del equipo de salud, ante situaciones adversas o negativas, es capaz de seleccionar aquellos aspectos de los cuales se puede extraer una lección; la cual se transforma en una mirada y conducta positiva extraída desde lo negativo, mejorando así ambas dimensiones y fortaleciéndose a sí mismo en su intersubjetividad. A su vez, el grupo también puede actuar resilientemente, siguiendo el mismo patrón para conseguir una mejor valoración, ahora no en lo individual si no que en lo grupal.

\section{Conclusiones}

En el ámbito de la salud el trabajo en equipo es una instancia en la que se interconectan el ethos personal con el ethos profesional que cada integrante del equipo encarna, de sus respectivas profesiones. Esto implica que, en la experiencia intersubjetiva que se establece entre profesionales provenientes de diferentes disciplinas, es factible encontrar distintas concepciones del "bien" y de "vida buena", lo que confirma la necesidad de una normativa moral que procure una forma de convivencia más o menos armónica y que otorgue espacios a todos los miembros del equipo para la expresión de sus respectivas perspectivas.

En este sentido, las proposiciones y distinciones de Ricoeur respecto de la ética permiten distinguir que la imagen de sí mismo (autoconcepto) y la estima de sí (autoestima) que tenga cada uno de los integrantes del equipo, son elementos centrales para la construcción y mantención de una experiencia intersubjetiva "armónica" al interior de los grupos de trabajo. Ricoeur, con este anclaje del momento deontológico kantiano (norma moral) en la intencionalidad teleológica aristotélica (vida buena), permite hacernos conscientes de cómo la imagen de sí mismo y la estima de sí se integran y articulan en la experiencia intersubjetiva que se da al interior del equipo de salud. De acuerdo con este filósofo, estos elementos serían determinantes a la hora de iniciarnos en un trabajo conjunto, coordinado e interdependiente, al que estamos llamados para lograr el objetivo común: "satisfacer las necesidades de salud del ser humano". La integración armónica de estos elementos permitiría tener clara conciencia de nuestras potencialidades y limitaciones para iniciarnos en este trabajo conjunto y, consecuentemente, estar más plásticos para detectar cuándo estamos - como dice Ricoeur - frente a un otro en condición de "solicitud", o cuándo nosotros mismos vivenciamos esta condición y requerimos se active en ese otro (que proviene de otra disciplina) esa espontaneidad benévola, que es intrínseca a la condición humana.

No podemos olvidar que el complejo escenario de salud que se presenta en la actualidad conmina a transitar, como "un todo interdisciplinario", desde un arraigado modelo biomédico, de saberes parcelados, focalizado en actividades procedimentales, a una perspectiva integral y holística, que hace imprescindible la construcción y mantención de relaciones y transacciones interpersonales sólidas entre los distintos miembros del equipo de salud.

Queda, como imperativo, abrirnos "tolerantes" a otras sensibilidades, reconocer y respetar a esos otros que provienen de otras disciplinas, que tienen otras formas de construir conocimiento y de accionar en salud, y, de esta forma, aunar esfuerzos para plantearnos creativamente frente a este 
Paul Ricoeur y una vida buena con otros y para otros - María Eugenia Rapimán Salazar et al.

complejo escenario en el que debemos trabajar Agradecemos a la profesora Ana Escríbar Wicks, como equipo, en pro de las mejores oportunida- por su inspiración. des de salud para las personas, familias y comunidades de nuestro país.

\section{Referencias}

1. Schein E. Psicología de la Organización. Ciudad de México: Editorial Prentice-Hall; 1982.

2. Talens F, Casabona I. Teorizar la práctica clínica asistencial de Enfermería: Un reto como profesión y disciplina. Cultura de los cuidados 2010; 14(28): 71-75.

3. Badillo J, Hernández A, Bermúdez A. La historia de enfermería: trascendencia del fenómeno cuidado y su relación con el tiempo. Cultura de los cuidados 2013; 17(36): 11-18.

4. Araos J. Ética de las virtudes y teleología: Aristóteles. En: Bioética fundamentos y dimensión práctica. Santiago de Chile: Editorial Mediterráneo; 2004: 23-48.

5. Escríbar A. Ética deontológica: Immanuel Kant. En: Bioética fundamentos y dimensión práctica. Santiago de Chile: Editorial Mediterráneo; 2004: 49-57.

6. Escríbar A. Ética narrativa: antecedentes y posibles aportes al juicio moral. Santiago de Chile: Ediciones Universidad Diego Portales; 2013.

7. Ricoeur P. Sí mismo como otro. Madrid: Siglo Veintiuno Editores; 2011.

8. Ricoeur P. Narratividad, fenomenología y hermenéutica. Trad. Gabriel Aranzueque. Cuaderno Gris, Época III, 1997; 2: 479-495.

9. Sachetti, F. Sé come un altro: L'etica della reciprocità nel pensiero di Paul Ricoeur. Società Mutamento Politica 2011; 2(4), 317-345.

10. Villa J. Vida buena y acción en la ética de Paul Ricoeur. Tópicos (México) 2015; 49.

Recibido: 3 de octubre de 2019

Aceptado: 18 de octubre de 2019 